\title{
Article \\ Appendicular Skeletal Muscle Mass Index and Physiological Performance in Post-Menopausal Women with Total Thyroidectomy
}

\author{
Wei-Lun Wen ${ }^{1,2,+}$, Hsiu-Chu Lin ${ }^{2,3,+}$, Hui-Chen Yu ${ }^{4}$, Yi-Pen Chen ${ }^{5}$, Ching-Chao Liang ${ }^{5}$, Wei-Hao Hsu ${ }^{1,2}$, \\ Jui-Sheng Hsu ${ }^{4,6}$, Ming-Chen Shih ${ }^{4,6}$, Mei-Yueh Lee ${ }^{2,7, *(\mathbb{D})}$ and Szu-Chia Chen 1,7,8,9,*(D)
}

\section{check for}

updates

Citation: Wen, W.-L.; Lin, H.-C.; Yu, H.-C.; Chen, Y.-P.; Liang, C.-C.; Hsu, W.-H.; Hsu, J.-S.; Shih, M.-C.; Lee, M.-Y.; Chen, S.-C. Appendicular Skeletal Muscle Mass Index and Physiological Performance in Post-Menopausal Women with Total Thyroidectomy. Appl. Sci. 2021, 11, 7555. https://doi.org/10.3390/ app11167555

Academic Editor: Alessandro de Sire

Received: 30 July 2021

Accepted: 17 August 2021

Published: 17 August 2021

Publisher's Note: MDPI stays neutral with regard to jurisdictional claims in published maps and institutional affiliations.

Copyright: (c) 2021 by the authors. Licensee MDPI, Basel, Switzerland. This article is an open access article distributed under the terms and conditions of the Creative Commons Attribution (CC BY) license (https:/ / creativecommons.org/licenses/by/ $4.0 /)$.
1 Department of Internal Medicine, Kaohsiung Municipal Siaogang Hospital, Kaohsiung 812, Taiwan; stevenwen760829@gmail.com (W.-L.W.); my345677@yahoo.com.tw (W.-H.H.)

2 Division of Endocrinology and Metabolism, Department of Internal Medicine, Kaohsiung Medical University Hospital, Kaohsiung 807, Taiwan; 830323@ms.kmuh.org.tw

3 Department of Nursing, Kaohsiung Medical University Hospital, Kaohsiung 807, Taiwan

4 Department of Medical Imaging, Kaohsiung Medical University Hospital, Kaohsiung 807, Taiwan; 1760192@yahoo.com.tw (H.-C.Y.); e3124@ms16.hinet.net (J.-S.H.); Stoneshih2007@gmail.com (M.-C.S.)

5 Department of Laboratory Technology, Kaohsiung Municipal Siaogang Hospital, Kaohsiung 812, Taiwan; 880475@kmhk.org.tw (Y.-P.C.); k670806@yahoo.com.tw (C.-C.L.)

6 Department of Radiology, Faculty of Medicine, College of Medicine, Kaohsiung Medical University, Kaohsiung 807, Taiwan

7 Faculty of Medicine, College of Medicine, Kaohsiung Medical University, Kaohsiung 807, Taiwan

8 Division of Nephrology, Department of Internal Medicine, Kaohsiung Medical University Hospital, Kaohsiung 807, Taiwan

9 Research Center for Environmental Medicine, Kaohsiung Medical University, Kaohsiung 807, Taiwan

* Correspondence: lovellelee@hotmail.com (M.-Y.L.); scarchenone@yahoo.com.tw (S.-C.C.)

+ These authors have contributed equally to this work and share first authorship.

\begin{abstract}
Sarcopenia is prevalent in postmenopausal women but is inconclusive in total thyroidectomy and under levothyroxine replacement. We aim to analyze the determinants of sarcopenia and investigate the early detection of sarcopenia in this group. Fifty postmenopausal women with total thyroidectomy were measured for body composition via Dual-energy X-ray Absorptiometry (DXA) and Appendicular Skeletal Muscle mass divided by the height square (ASM $\left./ \mathrm{ht}^{2}\right)$. Handgrip strength and gait speed and Geriatric Nutritional Risk Index (GNRI) were calculated. Eight determinants associated with sarcopenia include GNRI ( $\beta, 0.042 ; 95 \%$ confidence interval (CI), 0.021 to 0.064$)$, femoral neck BMD $(\beta, 0.989 ; 95 \%$ $\mathrm{CI}, 0.049$ to 1.929$)$, TSH ( $\beta, 0.192 ; 95 \% \mathrm{CI}, 0.027$ to 0.357$)$, and thyroglobulin $\mathrm{Ab}(0.657 ; 95 \% \mathrm{CI}, 0.210$ to 1.103) for ASM/height ${ }^{2}$; menopausal years $(\beta,-3.112 ; 95 \% \mathrm{CI},-5.661$ to -0.563$)$ and ASM $/$ height $^{2}$ $(\beta, 2.669 ; 95 \% \mathrm{CI}, 1.073$ to 4.265$)$ for handgrip strength; and GNRI ( $\beta, 0.062 ; 95 \% \mathrm{CI}, 0.019$ to 0.105$), \mathrm{T} 3$ $(\beta,-3.541 ; 95 \% \mathrm{CI},-7.019$ to -0.063$)$, and age $(\beta, 0.043 ; 95 \% \mathrm{CI}, 0.003$ to 0.084$)$ for gait speed. Our study confirmed a high prevalence of low skeletal muscle mass index in postmenopausal women with total thyroidectomy and revealed a number of determinants that could help early diagnosis and management this disease in daily clinical practice.
\end{abstract}

Keywords: sarcopenia; thyroidectomy; levothyroxine; postmenopausal women; Geriatric Nutritional Risk Index; skeletal muscle mass

\section{Introduction}

Sarcopenia, or low relative skeletal muscle index, is characterized by the age-related loss of skeletal muscle mass and strength and/or a reduction in physical performance [1]. It has attracted increasing attention worldwide as it has been shown to affect both motility and mortality [2]. Many endocrine and metabolic diseases and their interactions have been associated with sarcopenia, including aging, malnutrition, osteoporosis, diabetes, growth hormone deficiency, Cushing syndrome, hypogonadism, and thyroid dysfunction [3,4]. 
Previous studies have confirmed that overt thyroid dysfunction, regardless of whether it involves hypothyroidism or hyperthyroidism, has a harmful impact on muscle health $[5,6]$, as thyroid hormones play a role in skeletal muscle formation and function [7]. However, there is no known study that has yet investigated whether patients who have undergone total thyroidectomy and require long-term levothyroxine therapy are at a higher risk of developing sarcopenia.

Sarcopenia is also more frequently observed in postmenopausal women [8], and current menopausal management guidelines state that hormone replacement therapy combined with exercise may be beneficial to prevent the loss of muscle mass, performance, and strength [9]. A decrease in estrogen has been associated with muscle apoptosis and myosin dysfunction, possibly due to an increase in proinflammatory cytokines [10].

The detection of sarcopenia is challenging at outpatient clinics due to easily overlooked occult symptoms and expensive gold standard diagnostic methods [11]. Sarcopenia was clinically identified on the basis of the cutoff values derived from the Asian Working Group for Sarcopenia on the appendicular skeletal muscle index. The serum levels of biomarkers such as Interleukin 6 (IL-6), Insulin-like Growth Factor 1 (IGF-1), Macrophage migration Inhibitory Factor (MIF), and Secreted Protein Acidic Rich in Cysteine (SPARC) levels differed significantly between the healthy and sarcopenia groups [12]. Hence, the identification of surrogate laboratory markers of sarcopenia would be beneficial to increase the early diagnosis rate of sarcopenia $[13,14]$. Therefore, we conducted this study to analyze sarcopenia and its related determinants in postmenopausal women who had undergone total thyroidectomy.

\section{Materials and Methods}

\subsection{Study Population and Setting}

This single-centered, cross-sectional, observational study enrolled postmenopausal women $(n=50)$ with complete removal of thyroid, with or without reason for malignancy of thyroid, during their follow-up visits for prescription of Levothyroxine between 1 September 2019 and 31 December 2019 in southern Taiwan. We excluded from the study population those with amenorrhea for less than a year, those already receiving treatment for osteoporosis, and those who had undergone a thyroidectomy without complete removal of the thyroid. Calcium supplements were allowable during the study period. All clinical investigations were carried out in accordance with the principles of the Declaration of Helsinki. This study was approved by the Institutional Review Board of Kaohsiung Medical University Hospital (KMUHIRB-F(1)- 20190085), and all of the patients provided written informed consent.

\subsection{Demographic, Medical, and Laboratory Data}

Demographic and medical information, including age; gender; body weight and height for body mass index; and personal history including smoking, alcohol and lifestyle, medication history, operation history, especially on the gastrointestinal system and comorbid conditions, were obtained from the study patients' medical records and interviews by questionnaire. Biochemical measurements using standardized methods were performed in the central laboratory of Kaohsiung Medical University Hospital. Liver function profile, including serum aspartate aminotransferase (GOT) and alanine aminotransferase (GPT); thyroid function, including Thyroid Stimulating Hormone (TSH), free T4, T3, thyroglobulin, thyroglobulin and microsomal antibody, parathyroid hormone $(\mathrm{PTH})$, and total calcium; kidney function, including serum creatinine, and urine total protein and creatinine; and sex hormones, including follicular stimulating hormone (FSH), estradiol and testosterone, cortisol, and IGF-1 were measured. Each patient's blood samples were obtained for laboratory tests, including albumin level for GNRI calculation, which is an original nutritional risk index for older subjects, with a formula of GNRI $=(14.89 \times$ albumin $(\mathrm{g} / \mathrm{dL}))+(41.7 \times($ body weight $/$ ideal body weight $))$. General laboratory and specific osteoporosis evaluation markers, including bone resorption marker 
Carboxy-Terminal Collagen Crosslinks (CTX), Bone Alkaline Phosphatase (BALP), and vitamin D were measured.

\subsection{Bone Mineral Density (BMD) and Body Composition Measurements}

Body composition was measured using Dual-energy X-ray Absorptiometry (DXA) with a Horizon Wi DXA system (Hologic, Waltham, MA, USA). BMD was measured in the femoral neck, lumbar spine (L2-L4), and total hip. All data processing and scans were carried out by the same radiologic technologist to minimize differences in measurements. T-scores were used to compare normal individuals with the study subjects of the same race and sex with peak bone mass, as stated by the database of the manufacturer.

\subsection{Definition of Skeletal Muscle Mass Loss}

Because overall skeletal muscle mass is directly related to body size, the measured skeletal muscle mass had to be corrected for the body build of the study subject. The correction method involves dividing the appendicular skeletal muscle mass by the height square (ASM $/ \mathrm{ht}^{2}$ ), by body mass index (ASM/BMI), or by weight (ASM/weight). Most current studies, including the International Working Group on Sarcopenia (IWGS), the European Working Group on Sarcopenia in Older People (EWGSOP), and the Asian Working Group for Sarcopenia (AWGS), use skeletal muscle mass divided by height squared [15]. Therefore, we used ASM $/ \mathrm{ht}^{2}$ in this study, as assessed by DXA.

There are currently no research data for older people with regards to ASM $/ \mathrm{ht}^{2}$ cut-off points, and values lower than two standard deviations in younger people of the same ethnicity [14] or the lowest $20 \%$ of the study population [16] are usually used. For example, the IWGS recommends using cut-off points of the 20th percentile of the values of younger people of the same ethnicity as the benchmark, which they report as being $\leq 7.23 \mathrm{~kg} / \mathrm{m}^{2}$ for men and $\leq 5.67 \mathrm{~kg} / \mathrm{m}^{2}$ for women. The AWGS follows the recommendations of the EWGSOP and proposes cut-off points for muscle mass based on the body composition of Asians of $7.0 \mathrm{~kg} / \mathrm{m}^{2}$ for men and $5.7 \mathrm{~kg} / \mathrm{m}^{2}$ for women, if measured by Bioelectrical Impedance Analysis (BIA), and $7.0 \mathrm{~kg} / \mathrm{m}^{2}$ for men and $5.4 \mathrm{~kg} / \mathrm{m}^{2}$ in women if measured by DXA.

Therefore, we used ASM $/ \mathrm{ht}^{2}$ in this study, as assessed by DXA, and defined $\leq 5.4 \mathrm{~kg} / \mathrm{m}^{2}$ as the cut-off point.

\subsection{Criteria for Decreased Physiological Performance}

Muscle function is evaluated by muscle strength and physical performance. Muscle strength is measured by grip strength, knee flexion, knee extension, and peak expiratory flow [17], of which grip strength is most commonly used. Motility performance measures include gait speed, 6-min walk test, timed get-up-and-go test, and Short Physical Performance Battery (SPPB) [18]. There is currently no standard method to evaluate muscle function. For example, the EWGSOP and AWGS define a decline in muscle function as low grip strength and slow walking speed, whereas the IWGS uses walking speed alone. In our study, we applied the definition of EWGSOP and AWGS to determine the muscle function of the study population by using the methods of handgrip strength and gait speed.

\subsection{Statistical Analysis}

Descriptive statistics are presented as percentages, medians (25th-75th percentile), or means \pm standard deviations for non-normally distributed variables. G*Power 3.1.9.4 was used for the power analysis, and 0.996 of power (1- $\beta$ error probability) was obtained. The power analysis differences between groups were compared using the independent t-test for continuous variables and the chi-square test for categorical variables. Multiple stepwise linear regression analysis was used to identify the factors associated with $\mathrm{ASM} / \mathrm{ht}^{2}$, handgrip strength, and gait speed after multiple adjustments. A $p$ value $<0.05$ was determined to be statistically significant. All statistical analyses were produced using SPSS software for Windows version 19.0 (SPSS Inc., Chicago, IL, USA). 


\section{Results}

We enrolled a total of 50 menopausal women with a mean age of $61.92 \pm 7.77$ years who had undergone total thyroidectomy. Table 1 shows comparisons of the baseline and DXA characteristics between the patients with abnormal $\left(\leq 5.4 \mathrm{~kg} / \mathrm{m}^{2}\right)$ and normal $\left(>5.4 \mathrm{~kg} / \mathrm{m}^{2}\right) \mathrm{ASM} / \mathrm{ht}^{2}$. Compared to the patients with normal ASM $/ \mathrm{ht}^{2}$, those with abnormal ASM $/ \mathrm{ht}^{2}$ had lower ASM $/ \mathrm{ht}^{2}$, lower upper and lower extremity lean mass percentage, and lower handgrip strength.

Table 1. Comparison of baseline and Dual Energy X-ray Absorptiometry (DXA) characteristics between patients with normal and abnormal ASM/height ${ }^{2}$.

\begin{tabular}{|c|c|c|c|}
\hline Characteristics & $\begin{array}{c}\text { ASM/Height }{ }^{2}>5.4 \mathrm{~kg} / \mathrm{m}^{2} \\
(n=46)\end{array}$ & $\begin{array}{c}\text { ASM}_{(n=4)} \text { Height }^{2} \leq 5.4 \mathrm{~kg} / \mathrm{m}^{2} \\
(n=4)\end{array}$ & $p$ \\
\hline Age (year) & $61.96 \pm 7.99$ & $61.50 \pm 5.45$ & 0.912 \\
\hline Thyroid cancer $(\%)$ & 60.87 & 75.00 & 0.577 \\
\hline Menopausal years (year) & $12.50(8.75-20.25)$ & $13.00(8.50-22.00)$ & 0.718 \\
\hline GNRI (score) & $112.69 \pm 7.54$ & $112.48 \pm 6.11$ & 0.956 \\
\hline $\mathrm{BMI}\left(\mathrm{kg} / \mathrm{m}^{2}\right)$ & $24.70 \pm 3.44$ & $22.81 \pm 1.12$ & 0.284 \\
\hline \multicolumn{4}{|l|}{ DXA Parameters } \\
\hline Lumbar spine BMD $\left(\mathrm{g} / \mathrm{cm}^{3}\right)$ & $1.01 \pm 0.22$ & $1.02 \pm 0.17$ & 0.890 \\
\hline T score & $-1.44 \pm 1.80$ & $-1.38 \pm 1.46$ & 0.945 \\
\hline Femoral neck BMD $\left(\mathrm{g} / \mathrm{cm}^{3}\right)$ & $0.81 \pm 0.17$ & $0.79 \pm 0.14$ & 0.781 \\
\hline T score & $-1.61 \pm 1.25$ & $-1.83 \pm 1.04$ & 0.736 \\
\hline Total hip BMD $\left(\mathrm{g} / \mathrm{cm}^{3}\right)$ & $0.89 \pm 0.18$ & $0.87 \pm 0.13$ & 0.864 \\
\hline T score & $-0.92 \pm 1.44$ & $-1.10 \pm 1.06$ & 0.809 \\
\hline \multicolumn{4}{|l|}{ Body composition } \\
\hline ASM $/$ height $^{2}\left(\mathrm{~kg} / \mathrm{m}^{2}\right)$ & $6.21 \pm 0.59$ & $5.13 \pm 0.21$ & 0.001 \\
\hline Lean mass (trunk, \%) & $47.97 \pm 1.74$ & $49.05 \pm 1.22$ & 0.235 \\
\hline Lean mass (upper and lower extremity, \%) & $43.01 \pm 1.95$ & $40.72 \pm 0.79$ & 0.002 \\
\hline Fat (trunk, \%) & $54.70 \pm 4.84$ & $52.25 \pm 2.36$ & 0.325 \\
\hline Fat (upper and lower extremity, \%) & $41.06 \pm 4.65$ & $43.68 \pm 1.84$ & 0.273 \\
\hline \multicolumn{4}{|l|}{ Laboratory parameters } \\
\hline Albumin $(\mathrm{g} / \mathrm{dL})$ & $4.43 \pm 0.22$ & $4.65 \pm 0.32$ & 0.063 \\
\hline $\mathrm{eGFR}\left(\mathrm{mL} / \mathrm{min} / 1.73 \mathrm{~m}^{2}\right)$ & $85.62 \pm 16.47$ & $92.38 \pm 12.19$ & 0.429 \\
\hline Total calcium (mg/dL) & $8.91 \pm 0.37$ & $9.00 \pm 0.41$ & 0.642 \\
\hline TSH $(\mathrm{mU} / \mathrm{L})$ & $0.21(0.03-1.74)$ & $0.03(0.03-2.85)$ & 0.427 \\
\hline Free $\mathrm{T} 4(\mu \mathrm{g} / \mathrm{dL})$ & $1.69(1.44-2.00)$ & $1.61(1.39-2.03)$ & 0.762 \\
\hline T3 (ng/mL) & $74.20(66.01-88.10)$ & $93.90(72.17-115.02)$ & 0.108 \\
\hline PTH $(\mathrm{pg} / \mathrm{mL})$ & $28.18(21.95-32.21)$ & $34.58(21.17-41.17)$ & 0.414 \\
\hline Vitamin D (nmol/L) & $25.25(20.90-30.98)$ & $32.80(29.40-33.00)$ & 0.242 \\
\hline Bone ALP $(\mu \mathrm{g} / \mathrm{L})$ & $14.15(11.00-17.75)$ & $11.40(6.20-20.30)$ & 0.391 \\
\hline CTx (ng/mL) & $0.26(0.17-0.33)$ & $0.29(0.11-0.60)$ & 0.782 \\
\hline FSH (mIU/mL) & $41.81(27.19-34.54)$ & $35.68(28.22-51.10)$ & 0.953 \\
\hline Estradiol (pg/mL) & $19.68(15.48-25.37)$ & $26.68(20.46-31.91)$ & 0.514 \\
\hline Cortisol $(\mu \mathrm{g} / \mathrm{dL})$ & $10.63(8.48-12.33)$ & $11.49(9.34-13.23)$ & 0.583 \\
\hline IGF-1 (ng/mL) & $114.54(92.56-159.65)$ & $105.24(94.58-118.54)$ & 0.404 \\
\hline Testosterone (ng/dL) & $33.90(24.05-43.35)$ & $43.40(32.65-47.63)$ & 0.309 \\
\hline Thyroglobulin (IU/mL) & $0.16(0.16-0.16)$ & $0.16(0.16-0.16)$ & 0.521 \\
\hline Microsomal Ab (IU/mL) & $13.1(10.00-24.15)$ & $13.25(10.48-20.08)$ & 0.594 \\
\hline Thyroglobulin $\mathrm{Ab}(\mathrm{IU} / \mathrm{mL})$ & $20.00(20.00-20.00)$ & $20.00(20.00-20.00)$ & 0.556 \\
\hline Handgrip strength $(\mathrm{kg})$ & $20.22 \pm 4.00$ & $17.98 \pm 2.33$ & 0.278 \\
\hline Gait speed $(\mathrm{m} / \mathrm{s})$ & $5.89 \pm 1.13$ & $5.08 \pm 0.24$ & 0.001 \\
\hline
\end{tabular}

Abbreviations: Ab, antibody; ALP, Alkaline Phosphatase; ASM, appendicular skeletal muscle; BMD, bone mineral density; BMI, body mass index; CTx, C-terminal telopeptide; DXA, dual-energy X-ray absorptiometry; eGFR, estimated glomerular filtration rate; FSH, follicle-stimulating hormone; GNRI, geriatric nutrition risk index; IGF-1, Insulin-like growth factor-1; PTH, parathyroid hormone; TSH, Thyroid-stimulating hormone. 


\subsection{Determinants of $A S M / h t^{2}$ in the Study Patients}

Table 1 shows the determinants of $\mathrm{ASM} / \mathrm{ht}^{2}$ using multivariate stepwise linear regression analysis after adjusting for age; a history of thyroid cancer; log-transformed menopausal years; GNRI; DXA parameters; estimated Glomerular Filtration Rate (eGFR); total calcium; and log-transformed values of TSH, free T4, T3, PTH, vitamin D, BALP, CTx, FSH, estradiol, cortisol, IGF-1, testosterone, thyroglobulin, microsomal Ab, and thyroglobulin $\mathrm{Ab}$.

Table 2 shows Low GNRI (per 1 score; unstandardized coefficient $\beta, 0.042 ; 95 \%$ CI, 0.021 to $0.064 ; p<0.001$ ), low femoral neck BMD (per $1 \mathrm{~g} / \mathrm{cm}^{3}$; unstandardized coefficient $\beta, 0.989 ; 95 \%$ CI, 0.049 to $1.929 ; p=0.040$ ), low TSH (log per $1 \mathrm{mU} / \mathrm{L}$; unstandardized coefficient $\beta, 0.192 ; 95 \% \mathrm{CI}, 0.027$ to $0.357 ; p=0.024$ ), and low thyroglobulin $\mathrm{Ab}$ (log per $1 \mathrm{IU} / \mathrm{mL}$; unstandardized coefficient $\beta, 0.657 ; 95 \% \mathrm{CI}, 0.210$ to $1.103 ; p=0.005)$, which are all significantly associated with low ASM $/ \mathrm{ht}^{2}$.

Table 2. Determinants of ASM/height ${ }^{2}$ using multivariable stepwise linear regression analysis.

\begin{tabular}{|c|c|c|}
\hline ASM/Height ${ }^{2}$ & Multivariate (Forward) & \\
\hline & $\begin{array}{c}\text { Unstandardized Coefficient } \\
\beta(95 \% \mathrm{CI})\end{array}$ & $p$ \\
\hline GNRI (per 1 score) & $0.042(0.021,0.064)$ & $<0.001$ \\
\hline Femoral neck BMD (per $1 \mathrm{~g} / \mathrm{cm}^{3}$ ) & $0.989(0.049,1.929)$ & 0.040 \\
\hline $\mathrm{TSH}(\log$ per $1 \mathrm{mU} / \mathrm{L})$ & $0.192(0.027,0.357)$ & 0.024 \\
\hline Thyroglobulin $\mathrm{Ab}$ (log per $1 \mathrm{IU} / \mathrm{mL}$ ) & $0.657(0.210,1.103)$ & 0.005 \\
\hline
\end{tabular}

$\mathrm{R}^{2}=0.484$, F change $=9.317$, Durbin-Watson test $=1.826$.

The results were adjusted for age, history of thyroid cancer, log-transformed menopausal years, GNRI, DXA parameters, eGFR, total calcium, log-transformed T3, log-transformed free T4, log-transformed TSH, log-transformed thyroglobulin, log-transformed microsomal Ab and log-transformed thyroglobulin Ab, log-transformed PTH, log-transformed BALP, logtransformed CTx, log-transformed vitamin D, log-transformed FSH, log-transformed estradiol, log-transformed testosterone, log-transformed cortisol, log-transformed IGF-1. Abbreviations are the same as in Table 1.

\subsection{Determinants of Handgrip Strength in the Study Patients}

Table 3 shows the determinants of handgrip strength using multivariate stepwise linear regression analysis after adjusting for age; a history of thyroid cancer; log-transformed menopausal years; ASM $/ \mathrm{ht}^{2}$; GNRI; DXA parameters; eGFR; total calcium; and logtransformed values of TSH, free T4, T3, PTH, vitamin D, bone ALP, CTx, FSH, estradiol, cortisol, IGF-1, testosterone, thyroglobulin, microsomal $\mathrm{Ab}$, and thyroglobulin $\mathrm{Ab}$. A long duration of menopause (log per 1 year; unstandardized coefficient $\beta,-3.112 ; 95 \% \mathrm{CI}$, -5.661 to $-0.563 ; p=0.018$ ), and low ASM $/ \mathrm{ht}^{2}$ (per $1 \mathrm{~kg} / \mathrm{m}^{2}$; unstandardized coefficient $\beta, 2.669 ; 95 \%$ CI, 1.073 to $4.265 ; p=0.002$ ) were significantly associated with low handgrip strength.

Table 3. Determinants of handgrip strength using multivariable stepwise linear regression analysis.

\begin{tabular}{ccc}
\hline Handgrip Strength & Multivariate (Forward) & \\
\hline & Unstandardized Coefficient & $\boldsymbol{p}$ \\
\hline Menopausal years (log per 1 year) & $-3.112(-5.661,-0.563)$ & 0.018 \\
ASM $/$ height $^{2}\left(\right.$ per $\left.1 \mathrm{~kg} / \mathrm{m}^{2}\right)$ & $2.669(1.073,4.265)$ & 0.002 \\
\hline
\end{tabular}

$\mathrm{R}^{2}=0.325$, F change $=6.087$, Durbin-Watson test $=2.155$.

The results adjusted for age, history of thyroid cancer, log-transformed menopausal years, GNRI, DXA parameters, eGFR, total calcium, log-transformed T3, log-transformed 
free T4, log-transformed TSH, log-transformed thyroglobulin, log-transformed microsomal $\mathrm{Ab}$ and log-transformed thyroglobulin $\mathrm{Ab}$, log-transformed PTH, log-transformed BALP, log-transformed CTx, log-transformed vitamin D, log-transformed FSH, log-transformed estradiol, log-transformed testosterone, log-transformed cortisol, and log-transformed IGF-1. Abbreviations are the same as in Table 1.

\subsection{Determinants of Gait Speed in the Study Patients}

Table 4 shows the determinants of gait speed using multivariate stepwise linear regression analysis after multiple adjustments (variables as adjusted for handgrip strength in Table 2). Young age (per 1 year; unstandardized coefficient $\beta, 0.043 ; 95 \% \mathrm{CI}, 0.003$ to $0.084 ; p=0.036)$, high T3 $(\log$ per $1 \mathrm{ng} / \mathrm{mL}$; unstandardized coefficient $\beta,-3.541 ; 95 \% \mathrm{CI}$, -7.019 to $-0.063 ; p=0.046$ ), and low GNRI (per 1 score; unstandardized coefficient $\beta$, $0.062 ; 95 \% \mathrm{CI}, 0.019$ to $0.105 ; p=0.006$ ) were significantly associated with low gait speed.

Table 4. Determinants of gait speed using multivariable stepwise linear regression analysis.

\begin{tabular}{ccc}
\hline Gait Speed & Multivariate (Forward) & \\
\hline & Unstandardized Coefficient & $\boldsymbol{\beta}(\mathbf{9 5 \%}$ CI) \\
\hline Age (per 1 year) & $0.043(0.003,0.084)$ & 0.036 \\
GNRI (per 1 score) & $0.062(0.019,0.105)$ & 0.006 \\
T3 (log per 1 ng $/ \mathrm{mL})$ & $-3.541(-7.019,-0.063)$ & 0.046 \\
\hline $\mathrm{R}^{2}=0.280$, F change $=4.241$, Durbin-Watson test $=1.292$
\end{tabular}

The results were adjusted for age, history of thyroid cancer, log-transformed menopausal years, GNRI, DXA parameters, eGFR, total calcium, log-transformed T3, log-transformed free T4, log-transformed TSH, log-transformed thyroglobulin, log-transformed microsomal $\mathrm{Ab}$ and log-transformed thyroglobulin $\mathrm{Ab}$, log-transformed PTH, log-transformed BALP, log-transformed CTx, log-transformed vitamin D, log-transformed FSH, log-transformed estradiol, log-transformed testosterone, log-transformed cortisol, and log-transformed IGF-1. Abbreviations are the same as in Table 1.

\section{Discussion}

In this study, we identified eight determinants that were associated with sarcopenia in postmenopausal women who had undergone total thyroidectomy, of which GNRI was the only determinant to affect both muscle mass and physical function.

Several thyroid blood markers were related to ASM $/ \mathrm{ht}^{2} \leq 5.4$ in this study. First, low TSH, but not high free T4, was associated with low muscle mass. In contrast to these findings, a few studies have reported that high free T4 [19], high free T3 [20], or high free T3/free T4 ratio [20] were associated with sarcopenia, but low TSH was not [20]. However, these studies focused on older euthyroid subjects, and patients with subclinical or overt thyroid diseases were excluded. As mentioned previously, there is a clear relationship between overt thyroid dysfunction and sarcopenia. Although there is currently no clear conclusion as to whether or not subclinical thyroid dysfunction can affect muscle health, at least one study has reported no significant increased risk of low muscle mass in subclinical hypothyroid older people [21]. In addition, another study reported that subclinical hyperthyroidism was correlated with low muscle mass and strength [22]. Fewer studies [23,24] have focused on muscle health in patients who receive levothyroxine supplements; however, they did not quantify the contribution of determinants with regression analysis as in the present study. We confirmed the negative impact of levothyroxine over-replacement on muscle mass, and also found that TSH was a good index.

Second, thyroglobulin $\mathrm{Ab}$ was also positively associated with muscle mass, which has not previously been reported in patients without overt hypothyroidism. There are currently no recognized extra-thyroid targets of this specific autoantibody [25]; however, a study on hypothyroid myopathy found that these patients usually had higher thyroglobulin 
$\mathrm{Ab}$ than microsomal $\mathrm{Ab}$ [26], which seems to be the reverse of our results. A previous study reported that this autoantibody declined after thyroidectomy in thyroid carcinoma patients [27], and as more than $60 \%$ of our study population had this cancer, the lower autoantibody level may imply a longer duration of levothyroxine replacement therapy or over-suppression, which would therefore further increase the risk of sarcopenia.

Third, T3 was negatively associated with gait speed. This was peculiar but could still explain why T3 was correlated with gait speed but not with ASM $/ \mathrm{ht}^{2}$ or handgrip strength. Muscle mass itself is not equal to muscle quality [28], which is defined as muscle strength divided by muscle area. Walking or performing other physical activities requires both muscle power and also good vision, neural function, and coordination. A previous study attributed this to cognitive decline before a decline in muscle mass in subclinical hyperthyroidism patients [29]. Furthermore, another study reported a positive association between T3 and lower limb muscle mass but not upper limb muscle mass in euthyroid young men [30]. Nevertheless, this does not apply to our study directly because serum T3 levels were not correlated with free T4, TSH, or even supplemental doses taken by the levothyroxine replacement patients according to previous studies [31,32], so it appears to be an additional independent marker for physical performance in this specific population. This should serve as a reminder to routinely check for both TSH/free T4 and also T3 in patients receiving thyroxine replacement therapy to elucidate the risk of sarcopenia.

As an indicator of nutritional status, GNRI has been shown to be a predictor of sarcopenia in generally healthy older people [33], older cardiac patients [34], older patients with chronic obstructive pulmonary disease [35], patients under hemodialysis [36], and patients with early-stage non-small cell lung cancer [37]. However, to the best of our knowledge, this is the first study to prove this relationship in patients with total thyroidectomy.

Other determinants of sarcopenia in this study were low femoral neck BMD with low muscle mass, low ASM $/ \mathrm{ht}^{2}$ and long duration of menopause with weak handgrip strength, and young age with low gait speed. Except for the last factor, the other relationships are intuitive and have been reported in previous studies [38-41]. It is unclear why our older patients had higher gait speeds. However, this result should serve as a reminder to evaluate dynapenia in female patients post-thyroidectomy, even if they are relatively young, as they may have sufficient muscle quantity but poor quality. Moreover, poor muscle quality has been associated with hard outcomes such as all-cause mortality and hospitalization [42]. Furthermore, sarcopenia has also been shown to increase the incidence of falls and fractures, metabolic impairment, chemotherapy-related toxicity, depression, and decreasing quality of life [4,43].

Patients who undergo total thyroidectomy require lifelong levothyroxine therapy. In addition, if they are diagnosed with differentiated thyroid carcinoma and classified as being at high risk of recurrence or a structurally incomplete response, TSH over-suppression is recommended for longer relapse-free survival [44]. Current guidelines already emphasize the adverse effects of TSH suppression, including cardiovascular complications, osteoporosis, and cognitive dysfunction; however, they do not mention sarcopenia [44,45]. Nevertheless, greater attention should be paid to muscle health because proteolysis or muscle breakdown has been observed in early hyperthyroidism, along with an increased heart rate, with resolution of the abnormality after the resolution of hyperthyroidism [46]. For patients who need to keep taking levothyroxine over-replacement, aerobic activity training [23], resistance training [47], and additional protein supplements [48] have been shown to partially improve muscle health.

In our study population, the prevalence of $\mathrm{ASM} / \mathrm{ht}^{2} \leq 5.4$ was $8 \%$, which is similar to the $10 \%$ reported sarcopenia in healthy older women in previous studies [49]. Therefore, clinicians need to be aware of this common comorbidity in postmenopausal women with total thyroidectomy and try to prevent or manage it, as not doing do may result in a worse prognosis.

In this study, there are some limitations. First, we cannot assess longitudinal relationships between these parameters and ASM/height ${ }^{2}$ or physiological performance 
because it is a cross-sectional study. Second, we were not able to include a control group of healthy postmenopausal women of the same group as potential confounders because several parameters used in this study were age dependent. Lastly, it is not possible to use statistical tests to draw reliable conclusions because of the relatively small number of enrolled patients. Therefore, to confirm our results, we need follow-up large-scale studies.

\section{Conclusions}

We have identified several determinants related to sarcopenia in postmenopausal women of a younger age with total thyroidectomy, including low GNRI, low femoral neck $\mathrm{BMD}$, low TSH, and low thyroglobulin $\mathrm{Ab}$ for low ASM $/ \mathrm{ht}^{2}$; long duration of menopausal and low ASM $/ \mathrm{ht}^{2}$ for low handgrip strength; and low GNRI, high T3, and young age for low gait speed. Our findings suggest that, in postmenopausal women who have undergone total thyroidectomy, it is possible to recognize those at a high risk of low physiological performance and appendicular skeletal mass index, not only through BMD but also through parameters of thyroid function and its antibodies, as well as through nutritional status.

Author Contributions: Conceptualization, M.-Y.L. and M.-C.S.; methodology, H.-C.Y. and Y.-P.C.; data curation, H.-C.Y.,Y.-P.C., and C.-C.L.; software, W.-H.H. and J.-S.H.; validation, M.-Y.L.; resources, M.-Y.L.; formal analysis, S.-C.C.; investigation, S.-C.C.; writing-original draft preparation, W.-L.W. and S.-C.C.; writing-review and editing, H.-C.L. and S.-C.C.; visualization, W.-H.H.; project administration, J.-S.H.; funding acquisition, M.-Y.L.; supervision, J.-S.H. All authors have read and agreed to the published version of the manuscript.

Funding: This research was funded by Kaohsiung Medical University Hospital KMUH108-M802, KMUH108-M803, and KMUH108-M804.

Institutional Review Board Statement: This study was approved by the Institutional Review Board of Kaohsiung Medical University Hospital (KMUHIRB-F(1)- 20190085). The study was conducted according to the guidelines of the Declaration of Helsinki.

Informed Consent Statement: Informed consent was obtained from all subjects involved in the study.

Acknowledgments: We acknowledge the technical support given by Yin-Lan Kou and Ai-Jen Yang, and Yu-Ting Huang for statistical analysis.

Conflicts of Interest: The authors declare no conflict of interest.

\section{References}

1. Chen, L.K.; Woo, J.; Assantachai, P.; Auyeung, T.W.; Chou, M.Y.; Iijima, K.; Jang, H.C.; Kang, L.; Kim, M.; Kim, S.; et al. Asian Working Group for Sarcopenia: 2019 Consensus Update on Sarcopenia Diagnosis and Treatment. J. Am. Med. Dir. Assoc. 2020, 21, 300-307.e2. [CrossRef]

2. Li, R.; Xia, J.; Zhang, X.I.; Gathirua-Mwangi, W.G.; Guo, J.; Li, Y.; McKenzie, S.; Song, Y. Associations of Muscle Mass and Strength with All-Cause Mortality among US Older Adults. Med. Sci. Sports Exerc. 2018, 50, 458-467. [CrossRef]

3. McKee, A.; Morley, J.E.; Matsumoto, A.M.; Vinik, A. Sarcopenia: An Endocrine Disorder? Endocr. Pract. 2017, 23, 1140-1149. [CrossRef]

4. Borba, V.Z.C.; Costa, T.L.; Moreira, C.A.; Boguszewski, C.L. Mechanisms of Endocrine Disease: Sarcopenia in endocrine and non-endocrine disorders. Eur. J. Endocrinol. 2019, 180, R185-R199. [CrossRef]

5. Ramsay, I. Muscle Dysfunction in Hyperthyroidism. Lancet 1966, 288, 931-935. [CrossRef]

6. Martinez, F.J.; Bermudez-Gomez, M.; Celli, B.R. Hypothyroidism. A reversible cause of diaphragmatic dysfunction. Chest 1989, 96, 1059-1063. [CrossRef] [PubMed]

7. Bloise, F.F.; Oliveira, T.S.; Cordeiro, A.; Ortiga-Carvalho, T.M. Thyroid Hormones Play Role in Sarcopenia and Myopathies. Front. Physiol. 2018, 9, 560. [CrossRef] [PubMed]

8. Messier, V.; Rabasa-Lhoret, R.; Barbat-Artigas, S.; Elisha, B.; Karelis, A.D.; Aubertin-Leheudre, M. Menopause and sarcopenia: A potential role for sex hormones. Maturitas 2011, 68, 331-336. [CrossRef] [PubMed]

9. The NAMS 2017 Hormone Therapy Position Statement Advisory Panel. The 2017 hormone therapy position statement of The North American Menopause Society. Menopause 2017, 24, 728-753. [CrossRef] [PubMed]

10. Collins, B.C.; Laakkonen, E.K.; Lowe, D.A. Aging of the musculoskeletal system: How the loss of estrogen impacts muscle strength. Bone 2019, 123, 137-144. [CrossRef] [PubMed] 
11. Barbosa-Silva, T.G.; Menezes, A.M.B.; Bielemann, R.M.; Malmstrom, T.K.; Gonzalez, M.C.; Grupo de Estudos em Composição Corporal e Nutrição. Enhancing SARC-F: Improving Sarcopenia Screening in the Clinical Practice. J. Am. Med. Dir. Assoc. 2016, 17, 1136-1141. [CrossRef]

12. Kwak, J.Y.; Hwang, H.; Kim, S.K.; Choi, J.Y.; Lee, S.M.; Bang, H.; Kwon, E.S.; Lee, K.P.; Chung, S.G.; Kwon, K.S. Prediction of sarcopenia using a combination of multiple serum biomarkers. Sci. Rep. 2018, 8, 8574. [CrossRef]

13. Osaka, T.; Hamaguchi, M.; Hashimoto, Y.; Ushigome, E.; Tanaka, M.; Yamazaki, M.; Fukui, M. Decreased the creatinine to cystatin $\mathrm{C}$ ratio is a surrogate marker of sarcopenia in patients with type 2 diabetes. Diabetes Res. Clin. Pract. 2018, 139, 52-58. [CrossRef]

14. Calvani, R.; Marini, F.; Cesari, M.; Tosato, M.; Anker, S.D.; von Haehling, S.; Miller, R.R.; Bernabei, R.; Landi, F.; Marzetti, E.; et al. Biomarkers for physical frailty and sarcopenia: State of the science and future developments. J. Cachexia Sarcopenia Muscle 2015, 6, 278-286. [CrossRef]

15. Morley, J.E.; Abbatecola, A.M.; Argiles, J.M.; Baracos, V.; Bauer, J.; Bhasin, S.; Cederholm, T.; Coats, A.J.S.; Cummings, S.R.; Evans, W.J.; et al. Sarcopenia with limited mobility: An international consensus. J. Am. Med. Dir. Assoc. 2011, 12, 403-409. [CrossRef] [PubMed]

16. Delmonico, M.J.; Harris, T.B.; Lee, J.S.; Visser, M.; Nevitt, M.; Kritchevsky, S.B.; Tylavsky, F.A.; Newman, A.B.; Health, Aging and Body Composition Study. Alternative definitions of sarcopenia, lower extremity performance, and functional impairment with aging in older men and women. J. Am. Geriatr. Soc. 2007, 55, 769-774. [CrossRef]

17. Ishida, H.; Kobara, K.; Osaka, H.; Suehiro, T.; Ito, T.; Kurozumi, C.; Watanabe, S. Correlation between peak expiratory flow and abdominal muscle thickness. J. Phys. Ther. Sci. 2014, 26, 1791-1793. [CrossRef]

18. Guralnik, J.M.; Simonsick, E.M.; Ferrucci, L.; Glynn, R.J.; Berkman, L.F.; Blazer, D.G.; Scheer, P.A.; Wallace, R.B. A short physical performance battery assessing lower extremity function: Association with self-reported disability and prediction of mortality and nursing home admission. J. Gerontol. 1994, 49, M85-M94. [CrossRef] [PubMed]

19. Choi, Y.J.; Lee, Y.; Kim, K.-M.; Park, S.; Chung, Y.-S. Higher free thyroxine levels are associated with sarcopenia in elderly Koreans. Osteoporos. Sarcopenia 2015, 1, 127-133. [CrossRef]

20. Kong, S.H.; Kim, J.H.; Park, Y.J.; Lee, J.H.; Hong, A.R.; Shin, C.S.; Cho, N.H. Low free T3 to free T4 ratio was associated with low muscle mass and impaired physical performance in community-dwelling aged population. Osteoporos. Int. 2020, 31, 525-531. [CrossRef] [PubMed]

21. Moon, M.K.; Lee, Y.J.; Choi, S.H.; Lim, S.; Yang, E.J.; Lim, J.Y.; Paik, N.-J.; Kim, K.W.; Park, K.S.; Jang, H.C.; et al. Subclinical hypothyroidism has little influences on muscle mass or strength in elderly people. J. Korean Med. Sci. 2010, 25, $1176-1181$. [CrossRef] [PubMed]

22. Brennan, M.D.; Powell, C.; Kaufman, K.R.; Sun, P.C.; Bahn, R.S.; Nair, K.S. The impact of overt and subclinical hyperthyroidism on skeletal muscle. Thyroid 2006, 16, 375-380. [CrossRef] [PubMed]

23. Vigario Pdos, S.; Chachamovitz, D.S.; Cordeiro, M.F.; Teixeira Pde, F.; de Castro, C.L.; de Oliveira, F.P.; Vaisman, M. Effects of physical activity on body composition and fatigue perception in patients on thyrotropin-suppressive therapy for differentiated thyroid carcinoma. Thyroid 2011, 21, 695-700. [CrossRef] [PubMed]

24. Dubois, S.; Abraham, P.; Rohmer, V.; Rodien, P.; Audran, M.; Dumas, J.F.; Ritz, P. Thyroxine therapy in euthyroid patients does not affect body composition or muscular function. Thyroid 2008, 18, 13-19. [CrossRef]

25. Frohlich, E.; Wahl, R. Thyroid Autoimmunity: Role of Anti-thyroid Antibodies in Thyroid and Extra-Thyroidal Diseases. Front. Immunol. 2017, 8, 521. [CrossRef] [PubMed]

26. Sindoni, A.; Rodolico, C.; Pappalardo, M.A.; Portaro, S.; Benvenga, S. Hypothyroid myopathy: A peculiar clinical presentation of thyroid failure. Review of the literature. Rev. Endocr. Metab. Disord. 2016, 17, 499-519. [CrossRef] [PubMed]

27. Xu, J.; Bergren, R.; Schneider, D.; Chen, H.; Sippel, R.S. Thyroglobulin antibody resolution after total thyroidectomy for cancer. J. Surg. Res. 2015, 198, 366-370. [CrossRef]

28. Koster, A.; Ding, J.; Stenholm, S.; Caserotti, P.; Houston, D.K.; Nicklas, B.J.; You, T.; Lee, J.S.; Visser, M.; Newman, A.B.; et al. Does the amount of fat mass predict age-related loss of lean mass, muscle strength, and muscle quality in older adults? J. Gerontol. A Biol. Sci. Med. Sci. 2011, 66, 888-895. [CrossRef]

29. Ceresini, G.; Ceda, G.P.; Lauretani, F.; Maggio, M.; Bandinelli, S.; Guralnik, J.M.; Cappola, A.R.; Usberti, E.; Morganti, S.; Valenti, G.; et al. Mild thyroid hormone excess is associated with a decreased physical function in elderly men. Aging Male 2011, 14, 213-219. [CrossRef]

30. Roef, G.; Lapauw, B.; Goemaere, S.; Zmierczak, H.G.; Toye, K.; Kaufman, J.M.; Taes, Y. Body composition and metabolic parameters are associated with variation in thyroid hormone levels among euthyroid young men. Eur. J. Endocrinol. 2012, 167, 719-726. [CrossRef]

31. Livingston, M.; Birch, K.; Guy, M.; Kane, J.; Heald, A.H. No role for tri-iodothyronine (T3) testing in the assessment of levothyroxine (T4) over-replacement in hypothyroid patients. Br. J. Biomed. Sci. 2015, 72, 160-163. [CrossRef]

32. Al-Adsani, H.; Hoffer, L.J.; Silva, J.E. Resting energy expenditure is sensitive to small dose changes in patients on chronic thyroid hormone replacement. J. Clin. Endocrinol. Metab. 1997, 82, 1118-1125. [CrossRef]

33. Zhang, Y.; Fu, S.; Wang, J.; Zhao, X.; Zeng, Q.; Li, X. Association between Geriatric Nutrition Risk Index and low muscle mass in Chinese elderly people. Eur. J. Clin. Nutr. 2019, 73, 917-923. [CrossRef] 
34. Izawa, K.P.; Watanabe, S.; Oka, K.; Mogamiya, T.; Tada, M.; Nakata, S.; Nitobe, S.; Yoshizawa, K.; Hirano, Y.; Osada, N.; et al. Differences in physical performance based on the Geriatric Nutritional Risk Index in elderly female cardiac patients. Aging Clin. Exp. Res. 2015, 27, 195-200. [CrossRef]

35. Matsumura, T.; Mitani, Y.; Oki, Y.; Fujimoto, Y.; Ohira, M.; Kaneko, H.; Kawashima, T.; Nishio, M.; Ishikawa, A. Comparison of Geriatric Nutritional Risk Index scores on physical performance among elderly patients with chronic obstructive pulmonary disease. Heart Lung 2015, 44, 534-538. [CrossRef]

36. Beberashvili, I.; Azar, A.; Sinuani, I.; Shapiro, G.; Feldman, L.; Sandbank, J.; Stav, K.; Efrati, S. Geriatric nutritional risk index, muscle function, quality of life and clinical outcome in hemodialysis patients. Clin. Nutr. 2016, 35, 1522-1529. [CrossRef] [PubMed]

37. Shoji, F.; Matsubara, T.; Kozuma, Y.; Haratake, N.; Akamine, T.; Takamori, S.; Katsura, M.; Toyokawa, G.; Okamoto, T.; Maehara, Y. Relationship Between Preoperative Sarcopenia Status and Immuno-nutritional Parameters in Patients with Early-stage Non-small Cell Lung Cancer. Anticancer Res. 2017, 37, 6997-7003. [CrossRef] [PubMed]

38. Nielsen, B.R.; Abdulla, J.; Andersen, H.E.; Schwarz, P.; Suetta, C. Sarcopenia and osteoporosis in older people: A systematic review and meta-analysis. Eur. Geriatr. Med. 2018, 9, 419-434. [CrossRef]

39. Maltais, M.L.; Desroches, J.; Dionne, I.J. Changes in muscle mass and strength after menopause. J. Musculoskelet Neuronal Interact. 2009, 9, 186-197. [PubMed]

40. Cauley, J.A.; Petrini, A.M.; LaPorte, R.E.; Sandler, R.B.; Bayles, C.M.; Robertson, R.J.; Slemenda, C.W. The decline of grip strength in the menopause: Relationship to physical activity, estrogen use and anthropometric factors. J. Chronic Dis. 1987, 40, 115-120. [CrossRef]

41. Budziareck, M.B.; Pureza Duarte, R.R.; Barbosa-Silva, M.C.G. Reference values and determinants for handgrip strength in healthy subjects. Clin. Nutr. 2008, 27, 357-362. [CrossRef]

42. Legrand, D.; Vaes, B.; Matheï, C.; Adriaensen, W.; Van Pottelbergh, G.; Degryse, J.-M. Muscle strength and physical performance as predictors of mortality, hospitalization, and disability in the oldest old. J. Am. Geriatr. Soc. 2014, 62, 1030-1038. [CrossRef]

43. Prado, C.M.M.; Baracos, V.E.; McCargar, L.J.; Reiman, T.; Mourtzakis, M.; Tonkin, K.; Mackey, J.R.; Koski, S.; Pituskin, E.; Sawyer, M.B. Sarcopenia as a determinant of chemotherapy toxicity and time to tumor progression in metastatic breast cancer patients receiving capecitabine treatment. Clin. Cancer Res. 2009, 15, 2920-2926. [CrossRef]

44. Haugen, B.R.; Alexander, E.K.; Bible, K.C.; Doherty, G.M.; Mandel, S.J.; Nikiforov, Y.E.; Pacini, F.; Randolph, G.W.; Sawka, A.M.; Schlumberger, M.; et al. 2015 American Thyroid Association Management Guidelines for Adult Patients with Thyroid Nodules and Differentiated Thyroid Cancer: The American Thyroid Association Guidelines Task Force on Thyroid Nodules and Differentiated Thyroid Cancer. Thyroid 2016, 26, 1-133. [CrossRef]

45. Biondi, B.; Cooper, D.S. Benefits of thyrotropin suppression versus the risks of adverse effects in differentiated thyroid cancer. Thyroid 2010, 20, 135-146. [CrossRef]

46. Riis, A.L.; Jorgensen, J.O.; Ivarsen, P.; Frystyk, J.; Weeke, J.; Moller, N. Increased protein turnover and proteolysis is an early and primary feature of short-term experimental hyperthyroidism in healthy women. J. Clin. Endocrinol. Metab. 2008, 93, $3999-4005$. [CrossRef]

47. Landi, F.; Marzetti, E.; Martone, A.M.; Bernabei, R.; Onder, G. Exercise as a remedy for sarcopenia. Curr. Opin. Clin. Nutr. Metab. Care 2014, 17, 25-31. [CrossRef]

48. Beaudart, C.; Dawson, A.; Shaw, S.C.; Harvey, N.C.; Kanis, J.A.; Binkley, N.; Reginster, J.Y.; Chapurlat, R.; Chan, D.C.; Bruyère, O.; et al. Nutrition and physical activity in the prevention and treatment of sarcopenia: Systematic review. Osteoporos. Int. 2017, 28, 1817-1833. [CrossRef]

49. Shafiee, G.; Keshtkar, A.; Soltani, A.; Ahadi, Z.; Larijani, B.; Heshmat, R. Prevalence of sarcopenia in the world: A systematic review and meta- analysis of general population studies. J. Diabetes Metab. Disord. 2017, 16, 21. [CrossRef] 